numerical values for each of the ferromagnetics. The left side of the equation is thermal energy in mechanical units; and in order that the right side may also represent energy, $\mathrm{R} / a$ must play the part of a magnetic field. Now it is interesting to find that the expression for the maximum intrinsic magnetic field, as given by Van der Waals' equation, is $2 \mathrm{R} / a$ for iron and nickel, $3 \mathrm{R} / a$ for cobalt, and $6 \mathrm{R} / a$ for magnetite, and thus $\Delta \mathrm{C}$ may be easily expressed in terms of the intrinsic field if required.

Rochdale, November I9.

\section{Magnetic Boreholes.}

IN practical oilfield work many phenomena are met with and investigated from time to time, but one of these, namely, the magnetic state of some boreholes, does not appear to have received the attention it merits, and it would be interesting to learn the experiences and conclusions arrived at by practical oilfield men who have encountered this occurrence.

No doubt many oil men know of instances where tools and casing are found to be highly magnetised upon withdrawal from the borehole, as well as the lifting tackle and headgear in the derrick being affected in a similar manner to a lesser or greater degree.

Some little time ago an instance of this kind came under my notice. A pole became unscrewed while drilling, and the drilling bit with several poles attached remained in the borehole. As the casing was not moving freely, it was decided to move it before fishing for the lost tools; this was done, that is, the casing was raised and lowered several times from four to five feet. A fishing socket was then lowered in, which should have taken hold of the lost tools at about I I 5 feet off bottom, instead of which it was found that the top of the lost tools was at 70 feet from bottom, at which depth a hold was taken. At the time this difference in depth could not be accounted for, as it was known that the tools and rods had not run away, but had simply become detached, and their maximum possible fall of one foot could not have accounted for the loss of measurement. When the lost tools were brought to the surface the above-mentioned difference was explained, the rods which had been left behind having become bent more or less in the form of a helical spring. This coiling of the rods could be attributed to several ordinary causes as follows :

I. That the tools had fallen a long distance; this, however, was not the case.

2. That the fishing socket had been carelessly lowered in and the rods forced down. As every care was exercised when lowering in the socket, this could not have happened, and was proved by the fact that the rods above the socket were not in any way distorted.

3. That poles had got below the casing shoe when it was lifted and had been forced down when the casing was lowered into position. As the rods stood about roo feet inside the casing, this was obviously not possible.

4. It might be argued that one of the casing joints had caught the top of the poles or one of the pole joints when the casing was being let down. This is out of the question, because the casing was of the inserted joint type, perfectly flush on the inside, and careful examination showed no trace of catching.

This extraordinary occurrence of loss of distance and coiled rods could not be traced to any ordinary cause; and as it was known that the well was extremely magnetic, which was proved time after time by the condition of the tools whenever they were withdrawn from the borehole, as well as the magnetised state of the lifting tackle and derrick headgear, it would appear that the magnetic influence of the casing was the cause of the occurrence mentioned above.

$$
\text { NO. } 2827 \text {, VOL. I I } 3]
$$

One can assume that after the rods had become unscrewed they fell over to one side and rested for some considerable distance in contact with the casing, probably roo feet or more. The casing as a magnet had not sufficient power to lift the poles plus the drilling tools, but upon the casing being lowered into place each time after lifting it partly held and dragged the poles down with it owing to its magnetised condition, and at each subsequent lowering in the poles became more and more deformed.

It may be that highly magnetic boreholes may considerably affect drilling as well as fishing operations, whether with pole tools or with cable, therefore it would certainly be of interest to learn whether experiences of a similar nature have been met with and recorded.

Boryslaw, Galicia, Poland.

\section{Experiments on Ciona intestinalis.}

SincE I had the pleasure of making copies, the only ones, I think, of Dr. Kammerer's photographs of Ciona during his visit to England, and believe that Prof. MacBride is not at the moment in possession of a complete set, I am taking the liberty of supplying the details requested by $\mathrm{Mr}$. Cunningham in his letter to NATURE of December I 5 . I will, of course, forward prints to him at the earliest opportunity.

There are three photographs of Ciona. The first is of a single untreated specimen, the second of a group showing artificially produced var. macrosiphonica, and the third of two untreated offspring of the latter. In view of the various magnifications, both in the camera and from perspective, and since the whole of the animal is not visible in most cases, simple measurements would be meaningless. However, the increase of the siphon of $v$. macrosiphonica is chiefly in the direction of length, and therefore the ratios of length to breadth of the siphons provide a satisfactory method of comparing the specimens. The ratios are:

Photograph I. (Untreated, fully extended specimen.) Oral siphon $r \cdot 9$, aboral $x \cdot 65$;

Photograph II. (Group.) In a single fully extended specimen, doubtless that referred to by Prof. MacBride, the ratios are $2 \cdot 0$ oral and $x \cdot 65$ aboral. In the remainder the ratios when expanded are 4.0 to $4 \cdot 3$ oral and $2 \cdot 0$ to $4 \cdot 3$ aboral, and when contracted $2 \cdot 4$ oral and $I \cdot 9$ aboral.

Photograph III. One of these two young offspring of $v$. macrosiphonica is completely expanded or nearly so the other is quite contracted; in the former the ratios are $4 . \mathrm{I}$ oral and $2 \cdot 05$ aboral, in the latter they are $2 \cdot 35$ and $I \cdot 4$.

The validity of the means of comparison suggested above is shown by the ratios of length to breadth for the main part of the body lying, in all the four or five specimens in which it can be measured, between 4.1 and $4.8 ;$ i.e. the error due to varying expansion, position, and focus cannot possibly be more than 20 per cent., yet $v$. macrosiphonica shows an increase in length of the siphons of as much as I25 per cent.

With regard to the possibility of $v$. macrosiphonica falling within the limits of normal variation, the most valuable contribution appears to have been made by $\mathrm{Mr}$. Fox; the very extensive and apparently uniform
scale on which, in his experiment, elongation of the siphons failed to result from an altered technique seems to show very clearly, especially in the light of Dr. Kammerer's controls, that the effect is to be correlated with the particular nature of the operation as cause, and not with any normal variation which may be possible from one time to another, or with the nature of the food supply.

Lovell House, Leeds, December 18 . 